Article

\title{
Towards a Better Understanding of the Relationship between Individual's Self-Reported Connection to Nature, Personal Well-Being and Environmental Awareness
}

\author{
Kay Fretwell ${ }^{1}$ and Alison Greig ${ }^{2, *}$ \\ 1 School of Social and Political Science, University of Edinburgh, Edinburgh EH8 9LD, UK; \\ K.Fretwell@sms.ed.ac.uk \\ 2 Global Sustainability Institute, Anglia Ruskin University, Cambridge CB1 1PT, UK \\ * Correspondence: alison.greig@anglia.ac.uk
}

Received: 14 December 2018; Accepted: 28 February 2019; Published: 6 March 2019

\begin{abstract}
This paper examines the relationships between an individual's self-reported connection to nature (CTN) and aspects of their personal well-being (PWB) and environmental awareness. Specifically, it addresses (i) the relationship between CTN and PWB; (ii) the external variables which influence trait-level CTN over a person's life course and (iii) how individuals feel about CTN. A mixed methodology is used, with qualitative data adding depth and insight into the statistical associations recorded. The results are drawn from a sample of 222 respondents living in the City of Bath, UK. This study uncovered a significant relationship between CTN and some aspects of PWB which did not always align with research undertaken in other countries. Demographic variables, childhood experiences of nature, usual frequency of nature contact, and nature-related hobbies were all found to affect CTN. A number of barriers to CTN were also identified. Although the literature already provides considerable evidence of positive relationships between contact with nature and a range of mental and physical health benefits, the nature and mechanisms behind these relationships are not well understood, particularly for the UK population. As these associations are increasingly being used to underpin both health and environmental interventions and campaigns it is important that we better understand these relationships.
\end{abstract}

Keywords: connection to nature; personal well-being; environmental awareness; pro-environmental attitudes and behaviors; mixed methods

\section{Introduction}

There is a growing body of research that points to the positive relationships between connection to, and contact with, nature and a range of mental and physical health benefits (e.g., [1-4]). Exposure to nature has frequently been linked to reductions in stress [5-8], improvements in mood and alleviation of symptoms of depression [9-11]. People who feel more connected to nature may be more likely to spend time outdoors in nature and, in turn, gain associated health benefits [12,13]. There is also evidence that feeling connected to nature is linked to greater subjective personal well-being (PWB) [14-16] and constructive personality traits including conscientiousness, agreeableness, and openness to experience $[13,17]$. People who feel more connected to nature are also much more likely to exhibit pro-environmental attitudes and behaviors (PEAB) $[13,14,17]$, and have heightened concern about human impacts on the environment [12]. They are also more likely to identify as an environmentalist or belong to an environmental group [14,17]. 
Public health and environmental interventions are already happening based on the assumption that if connection to nature (CTN) can be increased in both intensity and reach, then positive health and environmental benefits will follow. Examples include the prescribing of so called 'green prescriptions' [18] that, in New Zealand, parts of Australia, the United States and now the UK, encourage patients to take part in 'outdoor activities' as a treatment for a range of mental and physical conditions. Several leading conservation charities have also established high profile campaigns to reconnect people with nature (e.g., $[19,20])$.

An in-depth understanding of the detailed relationships between CTN, PWB and PEAB is, however, lacking with published results from empirical research inconsistent. Different authors often use different methods, indicators and metrics. See Ives et al. [21] for a comprehensive review. Qualitative analysis of the relationship between CTN and PWB is particularly lacking. If we are to design effective interventions, it is essential we better understand these relationships.

The main aim of this work is to further our understanding of the complex relationship between connection to nature (CTN), personal well-being (PWB) and pro-environmental attitudes and behaviors (PEAB). It uses a mixed method approach to add depth and richness to quantitative data, helping also to reveal the mechanisms behind the correlations, and aims to help bring these separate groups of research together. This study is intended to guide future research, to help shape more effective intervention campaigns and promotional messages.

\section{Definitions}

The concept of 'nature' is a contested one in the literature and subjective for many individuals. For some it refers to all animals, plants, physical features and processes of the Earth that are not created by humans, whilst for others it may include features that were designed by humans but comprise substantial natural elements, such as parks and gardens. In this study the authors were not interested in individual's understanding or classification of nature per se, but rather how connected they feel to their own definition of nature, and how that affects well-being. Participants were therefore not provided with a specific definition of nature, as this would have restricted or influenced their CTN responses.

All humans are connected to nature in the sense that we are part of nature and depend upon it for survival. However, the term 'connection to nature' (CTN) is used here to refer to a subjective sense of physical, cognitive, emotional, or spiritual connectedness with the natural world. It is a measurable, trait-like construct, that is thought to be "relatively stable over time and across situations, though not completely fixed" [16] (p. 718). 'Nature contact' refers only to physical contact with the natural outdoors and does not assume a psychological element. The experience could be positive, negative or neutral.

'Personal well-being' (PWB) refers to how individuals evaluate their own lives from a hedonic (pleasure-seeking) perspective. It typically comprises an affective component (the extent to which a person experiences positive moods over negative moods) and an evaluative component (the extent to which a person feels satisfied with their life) [22,23]. The UK government's standard measures of PWB also include a eudemonic component (the extent to which a person feels a sense of meaning, worth, or purpose in life) [24]. In this paper, the term PWB will refer to a combination of affective, evaluative, and eudemonic aspects [22-25]. Like CTN, PWB is relatively stable. Though changes can occur over time, it does not tend to fluctuate with current mood [26].

\section{Measuring Connection to Nature (CTN)}

Much of the recent research surrounding CTN stem from Wilson's 'Biophilia Hypothesis' [27], which proposes an innate human affinity for the natural world that is inextricably linked to well-being. Kellert [28] claims that despite being universally inborn, cultural influences and life experiences can shape biophilia. Similarly, Orr [29] believes that biophilia is initially cultivated in childhood, but only as a result of diverse positive experiences of nature. In order to investigate theories arising from 
the 'Biophilia Hypothesis', several quantitative measures of CTN have been devised. Those most frequently used are summarized in Table 1.

Table 1. Measures of Connection to Nature (CTN).

\begin{tabular}{|c|c|c|c|}
\hline $\begin{array}{l}\text { Measures of } \\
\text { Connection to } \\
\text { Nature }\end{array}$ & Key Authors & Summary Description & Comments \\
\hline $\begin{array}{l}\text { Inclusion of } \\
\text { Nature in Self } \\
\text { (INS) }\end{array}$ & Schultz, 2001 [30] & $\begin{array}{l}\text { Participants select one of seven } \\
\text { pairs of overlapping circles } \\
\text { labelled 'self' and 'nature', that } \\
\text { best describes their relationship } \\
\text { with the natural environment. }\end{array}$ & $\begin{array}{l}\text { Very abstract, assumes participants can form a } \\
\text { conceptual image of their relationship with nature in } \\
\text { their mind [12]. }\end{array}$ \\
\hline $\begin{array}{l}\text { Connectedness } \\
\text { to Nature scale } \\
\text { (CNS) }\end{array}$ & $\begin{array}{l}\text { Mayer and } \\
\text { Frantz, 2004 [12] }\end{array}$ & $\begin{array}{l}\text { Designed to measure individuals' } \\
\text { emotional connection to the } \\
\text { natural world, using } 14 \text { statements } \\
\text { and a 5-point Likert scale }\end{array}$ & $\begin{array}{l}\text { Measures cognitive beliefs rather than emotional } \\
\text { connection. Self-referential wording of the } \\
\text { statements could account for correlation with other } \\
\text { positive scale measures such as well-being or } \\
\text { environmentalism [31]. }\end{array}$ \\
\hline $\begin{array}{l}\text { Nature } \\
\text { Relatedness' } \\
\text { scale (NR) }\end{array}$ & $\begin{array}{l}\text { Nisbet, Zelenski } \\
\text { and Murphy, } \\
2009[14]\end{array}$ & $\begin{array}{l}\text { Attempts to assess cognitive and } \\
\text { emotional connection, plus desire } \\
\text { for, and familiarity with, physical } \\
\text { connection with nature. } \\
\text { Uses } 21 \text { statements and a } \\
\text { 5-point Likert scale. }\end{array}$ & $\begin{array}{l}\text { Encompasses most elements of CTN. Divided into: } \\
\text { NR-Self-internalized thoughts and feelings relating } \\
\text { to one's personal relationship with nature; } \\
\text { NR-Perspective-an external nature-related } \\
\text { worldview and understanding of human impacts } \\
\text { on nature; } \\
\text { NR-Experience-a familiarity with and a desire for } \\
\text { physical connection with the natural world. }\end{array}$ \\
\hline
\end{tabular}

\subsection{Connection to Nature (CTN) and Personal Well-Being (PWB)}

Although the literature consistently reports a relationship between measures of $\mathrm{CTN}$ and various indicators of PWB, the results are inconsistent. Mayer and Frantz [12], for example, found a small, yet significant positive correlation between the CNS and life satisfaction $(n=135, r=0.20)$. They did not measure other aspects of PWB. Cervinka, Roderer and Hefler [13], who later tested the CNS against several measures of well-being, were unable to replicate Mayer and Frantz' findings with regards to life satisfaction. They also found no correlation with current mood. The CNS did, however, moderately correlate with having a sense of purpose in life in their study $(n=115, r=0.27)$.

Nisbet, Zelenski and Murphy [14] found their NR scale was significantly correlated with purpose in life ( $\mathrm{n}=184, \mathrm{r}=0.19)$ and positive affect $(\mathrm{n}=184, \mathrm{r}=0.29)$, but correlated with negative moods and life satisfaction only after controlling for other measures of environmentalism. Further studies by Zelenski and Nisbet [15] revealed that a short six-item version of the NR scale (NR-6) was distinctly associated with various measures of hedonic and eudemonic PWB, before and after controlling for other subjective connections ( $\mathrm{n}=415, \mathrm{r}=0.29$, partial $\mathrm{r}=0.22$ ). The other connections were tested using the same principle as Schultz' [30] but found that indicators of negative affect and depression were not found to be related to CTN. They speculate that CTN may boost positive moods rather than protect against negative moods. In a second separate study, NR-Self and NR-Experience correlated with positive affect (both $n=204 ; r=0.19$ ), but NR-Perspective did not. In fact, NR-Perspective was negatively associated with happiness $(r=-0.14)$ and life satisfaction $(r=-0.22)$ [15], which was assumed to be the result of pessimism caused by strong environmental attitudes.

Capaldi, Dopko and Zelenski [26] conducted a meta-analysis of 30 studies on CTN and happiness and concluded that, in general, people who feel more connected to nature are happier, though they found considerable variation across the measures, with correlation coefficients ranging from -0.01 to 0.42 . The strongest associations were between positive affect, life satisfaction, and INS. However, this contradicts Tam [17], who in a convergence study, found INS was consistently the weakest measure, and NR frequently the strongest. Neither study included eudemonic measures of PWB. 


\subsection{Connection to Nature and Personal Traits}

The impacts of demographic variables on CTN measures are underexplored in the literature, despite their potential to improve understanding of the basis of CTN and improve the targeting of CTN interventions. The results which do exist are once again inconsistent. For example, Mayer and Frantz [12] found no link between CNS scores and gender, age, childhood residence, or income. However, they report that scores did differ with education level in one of four studies (those with degrees felt more connected to nature than those without). In direct contrast, Cervinka, Roderer and Hefler [13], found CNS scores differed with gender (females felt more connected) and age (connection increased with age), but not with education level.

Klassen [32] investigated differences in CTN between urban $(n=42)$ and rural $(n=50)$ youths and found there was no relationship between residence and CNS scores. However, ten follow-up interviews revealed that rural youths were able to describe their connection with nature in much more depth and vivid detail than the urban participants, suggesting that a quantitative CNS score does not capture the full scope of CTN.

\subsection{Connection to Nature and Nature Contact}

Several studies provide evidence for Orr's theory [29] that the seeds of biophilia are planted through positive nature experiences (contact) during childhood. For example, Ward Thompson, Aspinall and Montarzino [33] found that childhood visits to woodlands and green spaces could partly predict subsequent adult visits, with the relationship strongest for those that rarely visited them. Other factors including gender and distance from home were also important.

Tam [17] found that frequency of childhood nature contact was significantly correlated with nine measures of CTN, although his use of a single-item question ("I spent a lot of time in nature during my childhood") as his metric for contact may reduce its validity. Nisbet, Zelenski and Murphy [16] also demonstrated moderate and significant correlation between NR scores and current frequency of time spent outdoors $(n=145, r=0.25)$, and stronger correlation with current frequency of time spent in nature $(\mathrm{n}=145, \mathrm{r}=0.30)$.

\subsection{Connection to Nature and Pet Ownership}

Nisbet, Zelenski and Murphy [16] found that, on average, pet owners felt more connected to nature than those who did not own pets (no pets $\mathrm{n}=72, \mathrm{~m}=3.15$ out of 5 ; pets $\mathrm{n}=111, \mathrm{~m}=3.37$ ).

\subsection{Causal Links}

Although each of the above studies report on a correlation between CTN and PWB, there is very little evidence for causation or the possibility that a third variable (e.g., nature contact) is causing changes in both (bivariate analysis). Another common limitation is the fact that measuring CTN and PWB relies on self-reporting. Although this is a popular method of data collection, it can introduce bias in the form of choice of scale (e.g., unipolar or bipolar, labelled or numerical), inaccurate recall, influence of current mood states, the placement of items in a questionnaire (i.e., earlier items influencing answers to later items), or concerns over confidentiality [34].

\section{This Study}

This study uses a mixed method approach to explore three specific questions;

Q1 What is the relationship between individual's self-reported CTN and PWB?

CTN is measured using the Nature Relatedness scale (NR), as it covers the greatest number of CTN dimensions and can be broken down into components. This allows an exploration of how individual aspects of CTN are linked to individual aspects of PWB and helps explain some of the inconsistencies reported in the literature. The NR scale demonstrates validity and reliability in its capacity to predict 
PEABs $[16,17]$. This study extends previous research by also assessing the relationship in a qualitative manner. By gathering opinions on CTN as a contributor to PWB, it is able to explore the mechanisms behind the relationship, and other factors that may affect the relationship. Finally, correlation between CTN and PWB is compared with nature contact and PWB, to explore whether CTN has unique implications above and beyond contact.

Q2 Which external variables may influence trait-level CTN over the life course?

Assuming the 'Biophilia Hypothesis' [27], consideration is given to factors that may influence CTN over a person's lifetime. Previous evidence suggests a link between childhood experiences and CTN, and usual frequency of nature contact and CTN. This is explored in more detail, taking into account qualitative responses, and nature-related activities or hobbies. Variance in NR scores across demographic variables are also considered, as this has been lacking in previous research.

Q3 How do participants feel about CTN, with regards to general awareness of, desire for, and barriers to connection?

Put simply, participants are asked to reflect on the concept of CTN in the following ways: Do they know what it is? Do they want more of it? And if so, what is stopping them? There are a multitude of CTN definitions and measures in an academic context, but public perception is also important. Awareness of attitudes towards and barriers to CTN are considered, aiming to discover potential gaps in public understanding, or emergent theories that might guide future research and potential intervention campaigns, or promotional messaging.

This study is fully compliant with Anglia Ruskin University's Research Ethics Policy. It was approved by the Faculty of Science and Technology ethics panel in May 2017.

\section{Methods}

This study used a combination of quantitative and qualitative data obtained simultaneously through online surveys. Quantitative data was used to test correlation between CTN and PWB, and with a range of variables with the potential to alter trait-levels of CTN (based on published literature). Qualitative data was used to provide a deeper understanding of some of these relationships, including possible causational mechanisms, and insight into people's awareness of, and desire for CTN, including barriers to connection. Surveys were administered using the Bristol Online Survey (BOS) survey tool. The questionnaire included a mix of single response, multiple response, Likert scale, and free-text questions (see Supplementary Materials).

The study was undertaken in a small, well-defined geographic area (the City of Bath) to minimize confounding variables such as participants' usual proximity to nature, and the quality and types of nature nearby. Participants were recruited using a non-random, non-representative convenience networking method, primarily utilizing local Facebook groups and email. Roberts [35] describes the strengths and weaknesses of sampling through online networking thusly: samples tend to under-represent those with limited finances and the elderly. Although they may have limited external validity, the method is suitable for exploratory research, it is also quick and easy to undertake compared to other methods, and allows for easy snowball sampling by 'sharing' posts or forwarding emails. The sample was not intended to be representative of the City of Bath, rather to provide hypotheses and focused suggestions for future research.

The survey was open from the end of June until the end of July 2017. Two hundred and twenty-two people completed the online questionnaire. Most respondents were female $(70.3 \%)$, and identified as 'white, British' (88.6\%). The most frequent age range was 35-44 years old (24.0\%), though 25-34 and $45-54$ age ranges were very close (22.2\% and $23.5 \%$ respectively). Most respondents were in paid employment or self-employed (72.0\%) and reported their highest level of education as undergraduate $(52.3 \%)$, followed by postgraduate $(29.7 \%)$. Most lived in the suburbs of a city or town $(52.1 \%)$, or in the city center $(27.2 \%)$. 
Quantitative data were analyzed using SPSS Statistics v.24 [36]. Shapiro-Wilk tests revealed the data was not normally distributed, so correlation coefficients were calculated using Spearman's rho. Qualitative data were analyzed manually using conventional content analysis. Coding themes were derived directly from the data, which is common practice when existing literature on the topic is limited [37].

\section{Results: The Relationship between Individual's Self-Reported Connection to Nature (CTN) and Personal Well-Being (PWB)}

\subsection{Nature Relatedness}

Nature relatedness (NR) scores range from one to five, with five representing the strongest CTN. The mean NR score in this study was $4.04(\mathrm{n}=222)$. NR scores were divided into the three components: NR-Self-internalized thoughts and feelings relating to one's personal relationship with nature; NR-Perspective - an external nature-related worldview and understanding of human impacts on nature; and NR-Experience-a familiarity with and a desire for physical connection with the natural world. Of the three, NR-Perspective had the highest mean $(\mathrm{m}=4.13)$ and also the lowest amount of variation $(\mathrm{sd}=0.57)$. NR-Experience had the lowest mean $(\mathrm{m}=3.97)$. This is detailed in Table 2.

Table 2. Mean Nature Relatedness (NR) scores.

\begin{tabular}{cccccccc}
\hline \multicolumn{2}{c}{ Overall NR Score } & \multicolumn{2}{c}{ NR-Self } & \multicolumn{2}{c}{ NR-Perspective } & \multicolumn{2}{c}{ NR-Experience } \\
\hline Mean & S.D. & Mean & S.D. & Mean & S.D. & Mean & S.D. \\
\hline 4.04 & 0.55 & 4.02 & 0.70 & 4.13 & 0.57 & 3.97 & 0.68 \\
\hline
\end{tabular}

\subsection{Personal Well-Being}

Individual indicators of PWB were measured on a scale of $0-10$. Higher scores are associated with greater well-being, with the exception of anxiety, where lower scores reflect greater well-being. The mean scores for each PWB indicator are detailed in Table 3 below.

Table 3. Mean Personal Well-being (PWB) scores.

\begin{tabular}{cccccccccccc}
\hline \multicolumn{2}{c}{ Life Satisfaction } & \multicolumn{4}{c}{ Worthwhile } & \multicolumn{2}{c}{ Happiness } & \multicolumn{3}{c}{ Anxiety } \\
\hline Mode & Mean & S.D. & Mode & Mean & S.D. & Mode & Mean & S.D. & Mode & Mean & S.D. \\
\hline $\begin{array}{c}7-10 \\
\text { (High PWB) }\end{array}$ & 7.00 & 1.74 & $\begin{array}{c}7-10 \\
\text { (High PWB) }\end{array}$ & 7.14 & 1.77 & $\begin{array}{c}7-10 \\
\text { (High PWB) }\end{array}$ & 6.88 & 1.83 & $\begin{array}{c}6-10 \\
\text { (Low PWB) }\end{array}$ & 4.51 & 2.38 \\
\hline
\end{tabular}

NR scores correlated with just one of the PWB indicators: "feeling that the things you do in life are worthwhile". The correlation was small, but significant $(\mathrm{r}=0.13, p<0.05)$. NR was not found to be associated with life satisfaction, happiness, or anxiety.

To determine which aspect of CTN was most linked to feeling worthwhile (Table 4), the three NR components were examined. Only NR-Self was significantly correlated with feeling worthwhile $(r=0.17$, $p<0.01)$ and the relationship was slightly stronger and more significant than that of overall NR.

Table 4. Nature Relatedness and Personal Well-being.

\begin{tabular}{ccccccccc}
\hline & \multicolumn{2}{c}{ Life Satisfaction } & \multicolumn{2}{c}{ Worthwhile } & \multicolumn{2}{c}{ Happiness } & \multicolumn{2}{c}{ Anxiety } \\
\cline { 2 - 8 } & Correlation & Sig. & Correlation & Sig. & Correlation & Sig. & Correlation & Sig. \\
\hline NR Score & 0.06 & 0.41 & $0.13^{*}$ & 0.05 & 0.06 & 0.36 & 0.02 & 0.75 \\
NR-Self & 0.09 & 0.17 & $0.17^{* *}$ & 0.01 & 0.07 & 0.31 & 0.01 & 0.87 \\
NR-Perspective & -0.02 & 0.78 & 0.1 & 0.14 & 0.03 & 0.61 & 0.01 & 0.85 \\
NR-Experience & 0.06 & 0.37 & 0.06 & 0.34 & 0.04 & 0.59 & 0.04 & 0.51 \\
\hline
\end{tabular}




\subsection{Nature Contact and Personal Well-Being}

There was a small but significant correlation between usual frequency of nature contact and two of the PWB indicators: worthwhile and happiness. Life satisfaction was also very close to being significantly correlated. The frequency of engagement in nature-related hobbies also correlated with feeling worthwhile and happy, and the effect was stronger than that of nature contact. Recent nature contact was not associated with PWB. None of the measures were associated with anxiety. Table 5 below provides details.

Table 5. Frequency of Nature Contact and Personal Well-being.

\begin{tabular}{ccccccccc}
\hline & \multicolumn{2}{c}{ Life Satisfaction } & \multicolumn{2}{c}{ Worthwhile } & \multicolumn{2}{c}{ Happiness } & \multicolumn{2}{c}{ Anxiety } \\
\cline { 2 - 9 } & Correlation & Sig. & Correlation & Sig. & Correlation & Sig. & Correlation & Sig. \\
\hline Usual contact & 0.13 & 0.05 & $0.14^{*}$ & 0.03 & $0.17^{*}$ & 0.14 & 0.03 & 0.70 \\
Recent contact & -0.03 & 0.68 & 0.04 & 0.55 & 0.09 & 0.20 & 0.04 & 0.54 \\
Regular hobbies & 0.11 & 0.11 & $0.17^{*}$ & 0.01 & $0.19^{* *}$ & 0.00 & 0.03 & 0.66 \\
\hline
\end{tabular}

Note: ${ }^{*}$ Correlation is significant at the 0.05 level (2-tailed) ${ }^{* *}$ Correlation is significant at the 0.01 level (2-tailed).

All 156 respondents who provided a free-text answer described at least one positive link between CTN and PWB. Thirty-one described general improvements in well-being and 120 described one or more specific positive effects (Figure 1).

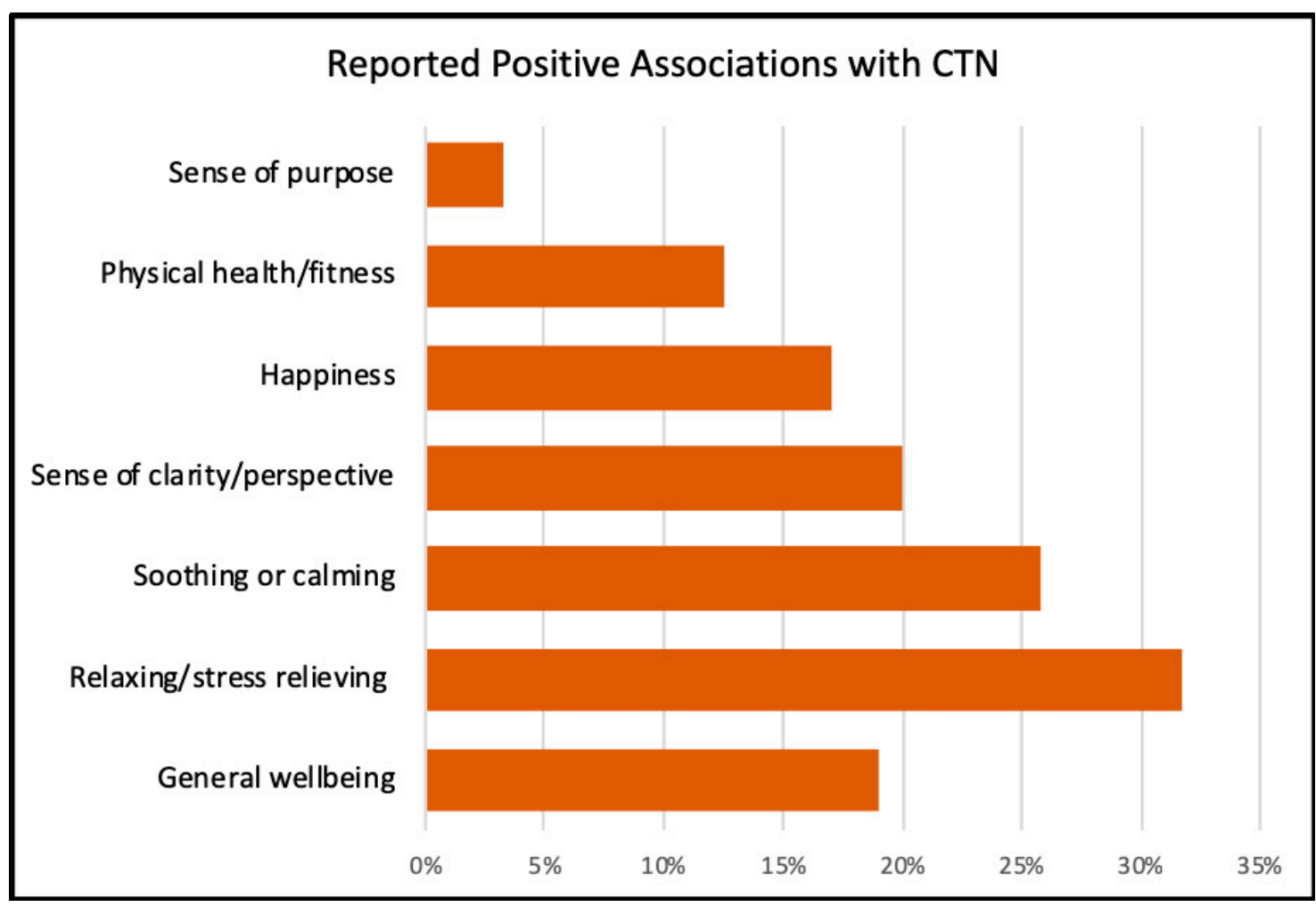

Figure 1. Positive associations between Connection to Nature and Personal Well-being $(n=156)$.

Seventy-six respondents provided free text comments describing nature-related activities they believed increase PWB. The three most frequently mentioned related to; generally spending time in nature $(25 \%)$, appreciating the wonder or beauty of nature $(22.4 \%)$, and walking or hiking $(18.4 \%)$ (Figure 2).

Eighty-five respondents described the mechanisms by which CTN or nature contact might affect PWB. The majority of responses related to the following themes: 
- Escape from modern life e.g., "disconnect from city life"; "not having messages of consumerism rammed dwn[sic] our throat", "time away from electronic media"

- Time for reflection or meditation e.g., "it gives you time to clear your mind"; "there is a medatitive[sic] experience in being alone with nature"; "time to reflect"

- Fresh air e.g., "breathing in fresh air makes people happier"; "better air quality"

- Peace and quiet e.g., "tranquility"; "being somewhere quiet where things are calmer also helps reduce stress-levles[sic]"; "stillness and peace"

- Spirituality e.g., "tremendous spiritual energy"; "get in touch with a deeper reality"

- Sunlight e.g., "natural sunlight"; "exposure to natural light"

One hundred and twenty-six respondents answered a second free-text question about the importance of CTN in comparison to other factors that may improve PWB (e.g., diet, exercise, work life, social life). Only one person felt it was unimportant and a further five felt it only played a minor role. The relative importance the remaining 122 respondents placed on CTN is represented in Figure 3.

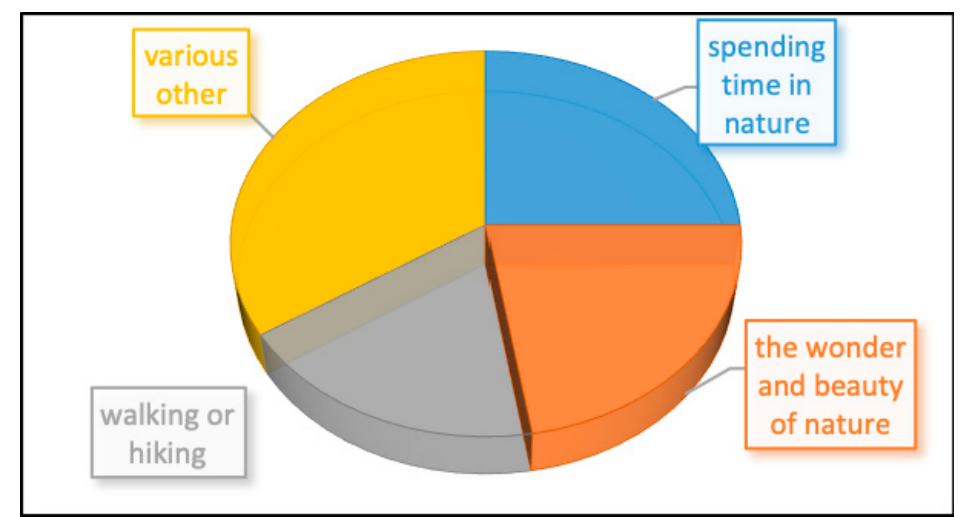

Figure 2. Activities which increase Personal Well-being $(n=76)$.

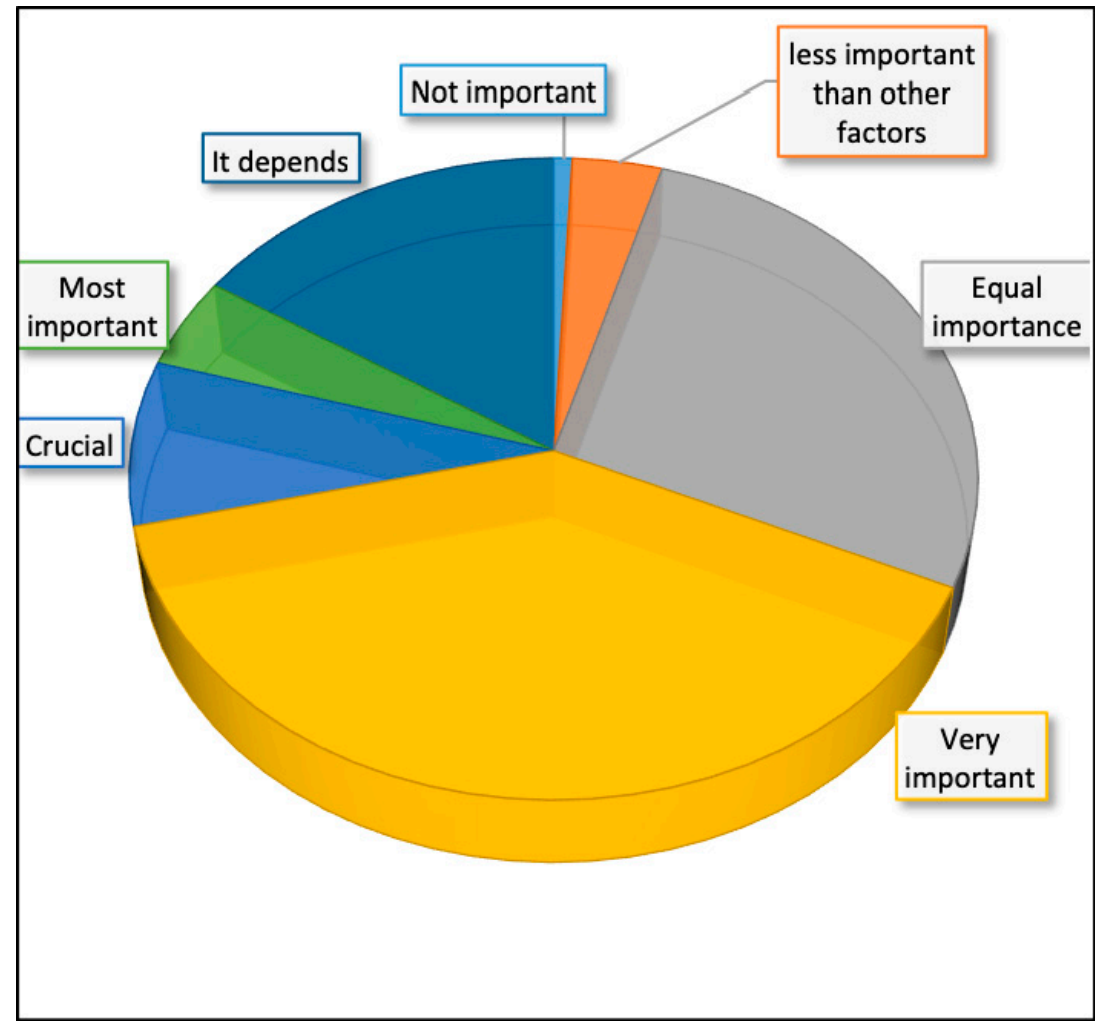

Figure 3. Relative importance of Connection to Nature to Personal Well-being $(n=126)$. 
4.4. External Variables Influence on Trait-Level Connection to Nature over Life Course

\subsubsection{Demographics}

On average, females (NR 4.09) felt more connected to nature than males (NR 3.90), with mean NR scores peaking in the 55-64 age bracket (Figure 4).

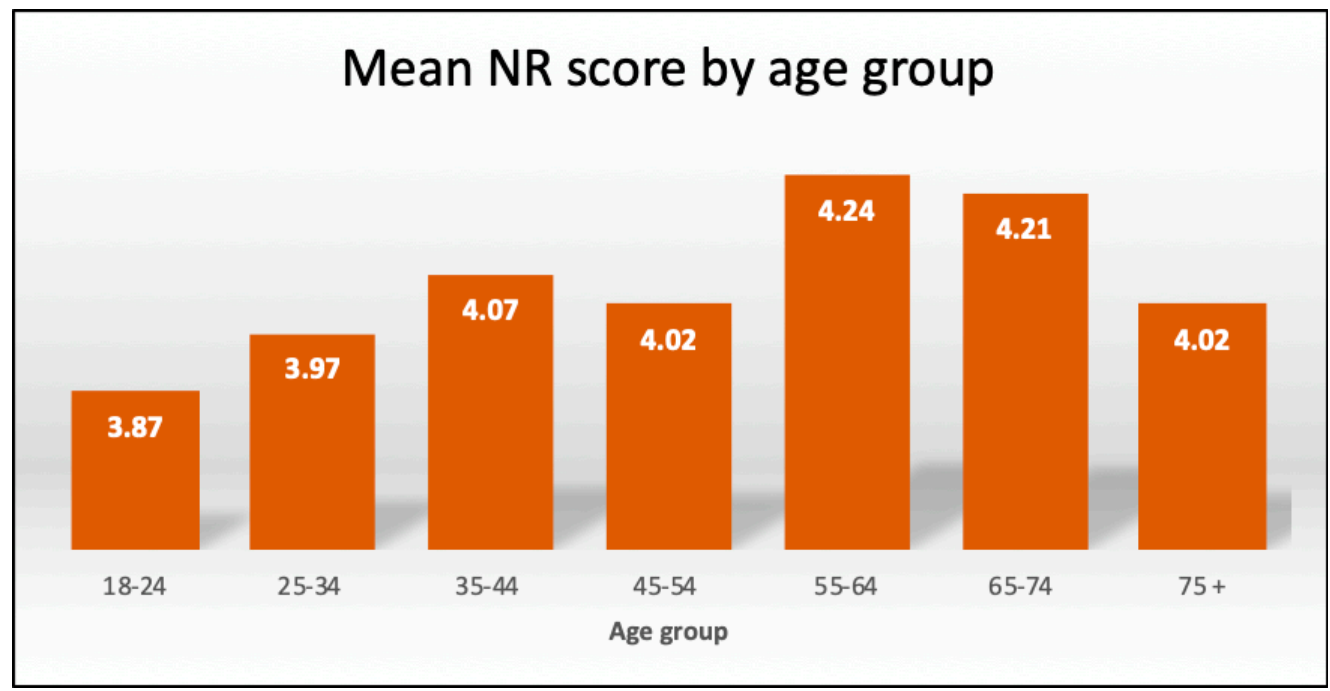

Figure 4. Nature Relatedness score and age.

Respondents who identified as white (NR 4.1) felt more connected to nature than other ethnicities (NR 3.7). Those whose highest qualification was an undergraduate degree felt less connected now than when they were at school or college. Those that reported their primary employment status as retired or volunteer felt the most connected, overall and current students the least connected, followed by full-time employed (Figure 5). People who lived in rural areas felt most connected, and those in urban areas least connected.

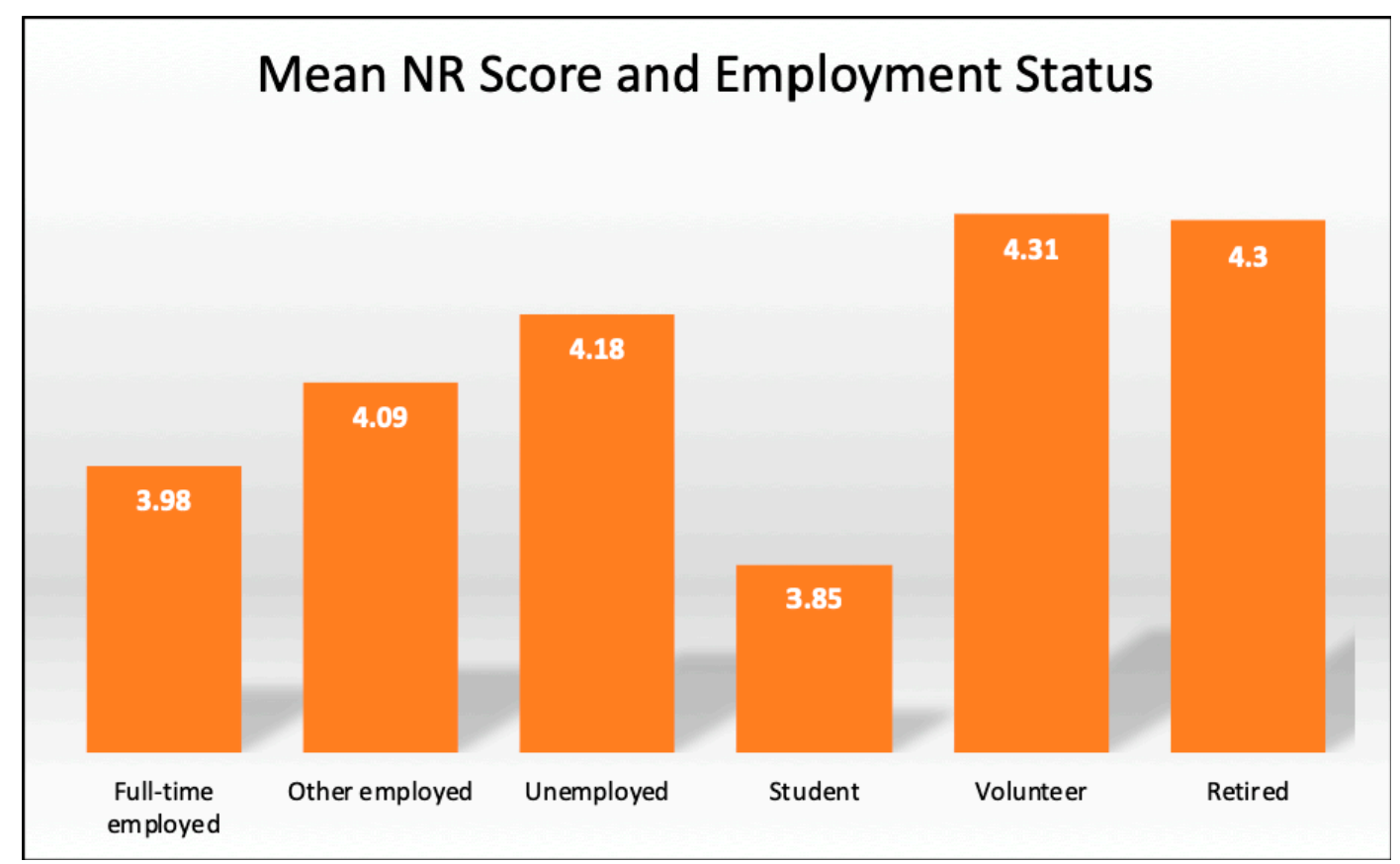

Figure 5. Relatedness and employment. 


\subsubsection{Childhood Experiences}

Overall NR scores were not found to be significantly associated with frequency of outdoor play in childhood, although the small correlation between NR-Experience and outdoor play was almost significant $(r=0.13, p=0.05)$. Correlation between overall NR scores and frequency of physical interaction with nature in childhood (e.g., climbing trees, digging in mud, handling insects) was small yet significant $(r=0.15, p<0.05)$, and NR-Experience was the most important component in this relationship ( $\mathrm{r}=0.16, p<0.05)$. Childhood residence did not significantly correlate with overall NR scores, but did correlate with NR-Experience $(\mathrm{r}=0.16, p<0.05) .{ }^{*}$ Correlation is significant at the 0.05 level (2-tailed).

One hundred and fifty-nine of the 222 participants answered a free-text question on the influence of childhood experiences on current thoughts or feelings about the natural world. Only 16 stated that it had little to no effect, with 121 describing specific experiences in their childhood that they believed were influencing factors. The majority of responses related to the following themes:

- Spending time outdoors e.g., "I spent a lot of time outside"

- Parental influence e.g., "my parents instilled an appreciation of nature into me"

- Wildlife e.g., "loads of wildlife in the back garden"; "interacted with cows and birds"

- Walking or hiking e.g., "going for walks in the forest"

- Rural upbringing e.g., "growing up in a rural location gave me a natural education"

- Physical interaction e.g., "enjoyment included climbing trees, building dens"

- Forests or trees e.g., "I was very fortunate living across from a large woodland"

- Social connections e.g., "walking in the woods with an aunt and uncle"

Seventy-eight described the specific effects they believed these childhood experiences had on their adult life. The majority of responses related to the following themes:

- General appreciation of nature e.g., "Made me appreciate [nature]. See its beauty"

- Increased desire for nature experiences e.g., "increased my need to be in the nature"

- Increased respect for nature e.g., "definitely[sic] made me respect nature"

- Increased knowledge of nature e.g., "completely shaped my current [...] knowledge of nature"

- Love of animals e.g., "especially love animals, [this has] carried on throughout my adult life"

- Safety and comfort e.g., "I feel safe and comfortable in nature environments"

- Desire to pass it on to the next generation e.g., "hopefully will continue in my children too"

- Awareness of environmental issues e.g., "I have grown conscious of the fact that we are rapidly destroying our planet"

\subsubsection{Nature in Everyday Life}

There was strong and significant correlation between NR scores and usual frequency of nature contact, recent nature contact and frequency of nature-related hobbies $(r=0.45, p<0.01 ; \mathrm{r}=0.37$, $p<0.01 ; \mathrm{r}=0.44, p<0.01$ respectively). Of the three NR components, the relationship was strongest with NR-Experience for average and recent contact $(\mathrm{r}=0.42 ; \mathrm{r}=0.43$ respectively), and NR-Self for hobbies $(r=0.42)$. Usual nature visits were also significantly correlated with all measures of childhood experiences. This is detailed in Table 6 below.

Figure 6 below compares mean NR scores against different types of regular nature-related hobbies. All hobbies were related to higher than average CTN. Respondents whose regular hobbies were bird-watching, wildlife-spotting, or volunteering for a nature-related charity felt most connected, whilst those that did not have any nature-related hobbies were less connected by a considerable margin. Pet ownership (childhood and current) was not found to be associated with NR scores in any way. 
Table 6. Correlation between Connection to Nature and Nature Contact $(\mathrm{n}=221)$.

\begin{tabular}{ccccccc}
\hline & \multicolumn{2}{c}{ Usual Contact } & \multicolumn{2}{c}{ Regular Hobbies } & \multicolumn{2}{c}{ Recent Contact } \\
\cline { 2 - 7 } & Correlation & Sig. & Correlation & Sig. & Correlation & Sig. \\
\hline Overall NR score & $0.45^{* *}$ & 0.00 & $0.44^{* *}$ & 0.00 & $0.37^{* *}$ & 0.00 \\
NR-Self & $0.40^{* *}$ & 0.00 & $0.42^{* *}$ & 0.00 & $0.28^{* *}$ & 0.00 \\
NR-Perspective & $0.28^{* *}$ & 0.00 & $0.25^{* *}$ & 0.00 & $0.21^{* *}$ & 0.00 \\
NR-Experience & $0.42^{* *}$ & 0.00 & $0.40^{* *}$ & 0.00 & $0.43^{* *}$ & 0.00 \\
Childhood experiences & & & & & & \\
Outdoor play & $0.15^{*}$ & 0.02 & 0.11 & 0.12 & 0.09 & 0.17 \\
Interacting with nature & $0.14^{*}$ & 0.04 & 0.10 & 0.15 & 0.03 & 0.69 \\
Childhood residence & $0.16^{*}$ & 0.02 & 0.12 & 0.08 & 0.12 & 0.09 \\
\hline
\end{tabular}

Note: ${ }^{*}$ Correlation is significant at the 0.05 level (2-tailed) ${ }^{* *}$ Correlation is significant at the 0.01 level (2-tailed).

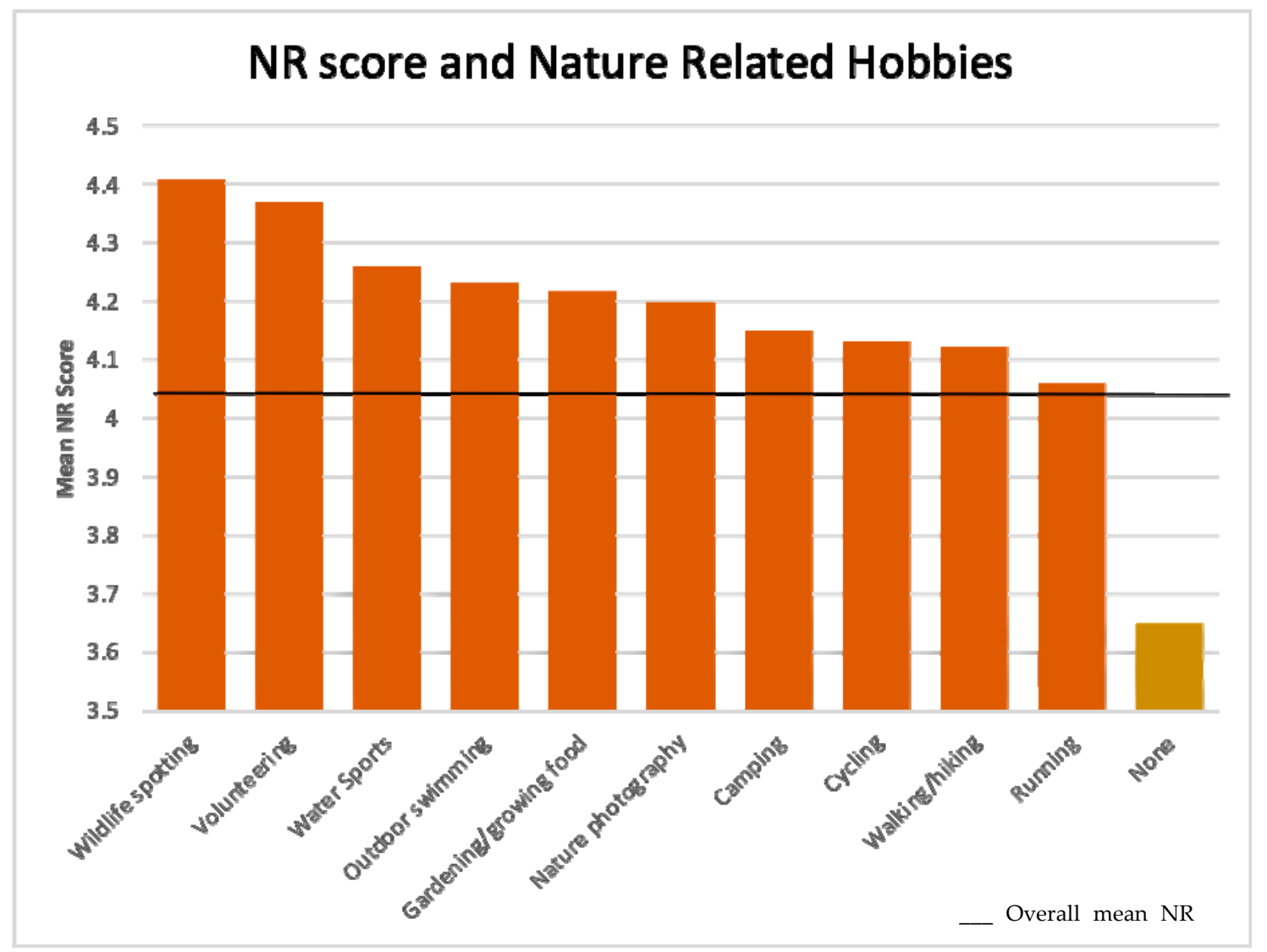

Figure 6. Nature-related hobbies and Nature Relatedness.

\subsection{Awareness of, Desire for, and Barriers to Connection to Nature}

\subsubsection{Awareness of the Concept of Connection to Nature}

One hundred and fifty-six of the 222 respondents answered a free-text question which asked for an explanation of what CTN meant to them. The majority (44.3\%) described CTN using just one dimension, but for more than half it was multidimensional. Thirty-four point five percent described two dimensions, $17.3 \%$ described three dimensions and $2.9 \%$ described four dimensions. Only six definitions included negative opinions (e.g., "hippie rubbish"; "a slightly irritating term"). Responses most frequently related to human interconnectedness with nature $(22.8 \%)$, positive thoughts or feelings about nature (21.4\%), and enjoyment of physical experiences of nature $(20.0 \%)$.

The main themes which emerged related to: 
- A nature-related worldview-i.e., an understanding or awareness of;

- human interconnectedness with nature (e.g., "the awareness that we are part of nature")

- human impacts on nature (e.g., "understanding that [...] our actions can have a negative impact")

- The importance of nature to humans (e.g., "to understand that we as human beings cannot do without nature")

- Nature-related identity (e.g., "whether it is part of your being or separate from you and your life")

- Possessing pro-environmental attitudes (e.g., "the awareness that [ . . ] as humans we have a responsibility to take care of [nature]"

- Engaging in pro-environmental behaviors (e.g., "caring about the environment enough to make different choices")

- Positive thoughts or feelings about nature (e.g., "it is about having a positive emotional response to nature")

- Enjoyment of physical experiences of nature (e.g., "enjoying spending time outside in rural areas")

- Spiritual responses to nature (e.g., "being [...] spiritually inspired and enhanced by the natural world")

- Seeing nature as a source of well-being (e.g., "understanding how nature can affect your wellbeing and how you act upon that")

- General interest in, or appreciation of nature (e.g., "appreciation and observance of nature")

One hundred and forty-one respondents claimed they had thought about the idea of CTN before undertaking the survey, $26.5 \%$ claimed they had thought about their own personal CTN, $13.6 \%$ claimed CTN was "just part of my life" or "I have always felt this way" and $12.9 \%$ had considered it in the context of concern about human impacts on the environment. Nine point eight percent had encountered it in an academic context, a further $4.5 \%$ had personally researched it, and $4.5 \%$ had encountered it through their work.

\subsubsection{Awareness of Personal CTN}

After providing their own descriptions of CTN, participants were provided with a definition adapted from Nature Relatedness Research [38] and Nisbet, Zelenski and Murphy [16]. All 222 participants were then asked how connected to nature they thought they were based on this definition using a five-point Likert scale. Forty-five percent of participants' scores matched their rounded NR scores exactly, $32.9 \%$ of scores differed by a small amount ( 0.26 to 0.5$)$ and only $6.3 \%$ differed by more than 1 . Almost the same number overestimated as underestimated. This indicates the NR metric is a meaningful representation of individuals subjective connection to nature.

\subsubsection{Barriers to Connection to Nature}

One hundred and eighty-eight of the 222 participants stated they wished they could spend more time connecting with nature. For the vast majority $(84 \%)$ lack of time was one of the primary barriers (Figure 7). The 34 participants who stated they did not want to spend more time connecting with nature had much lower NR scores $(\mathrm{m}=3.77)$ than average $(\mathrm{m}=4.04)$, but higher PWB, with the exception of feeling worthwhile $(\mathrm{n}=34, \mathrm{~m}=7.06 ; \mathrm{n}=222, \mathrm{~m}=7.14)$. Of this 34 , more than half $(56.4 \%)$ claimed they were content with the amount of time they spend connecting with nature, with other frequent reasons including "I prefer to spend my time doing other things" and "I just don't see the need to connect with nature". 


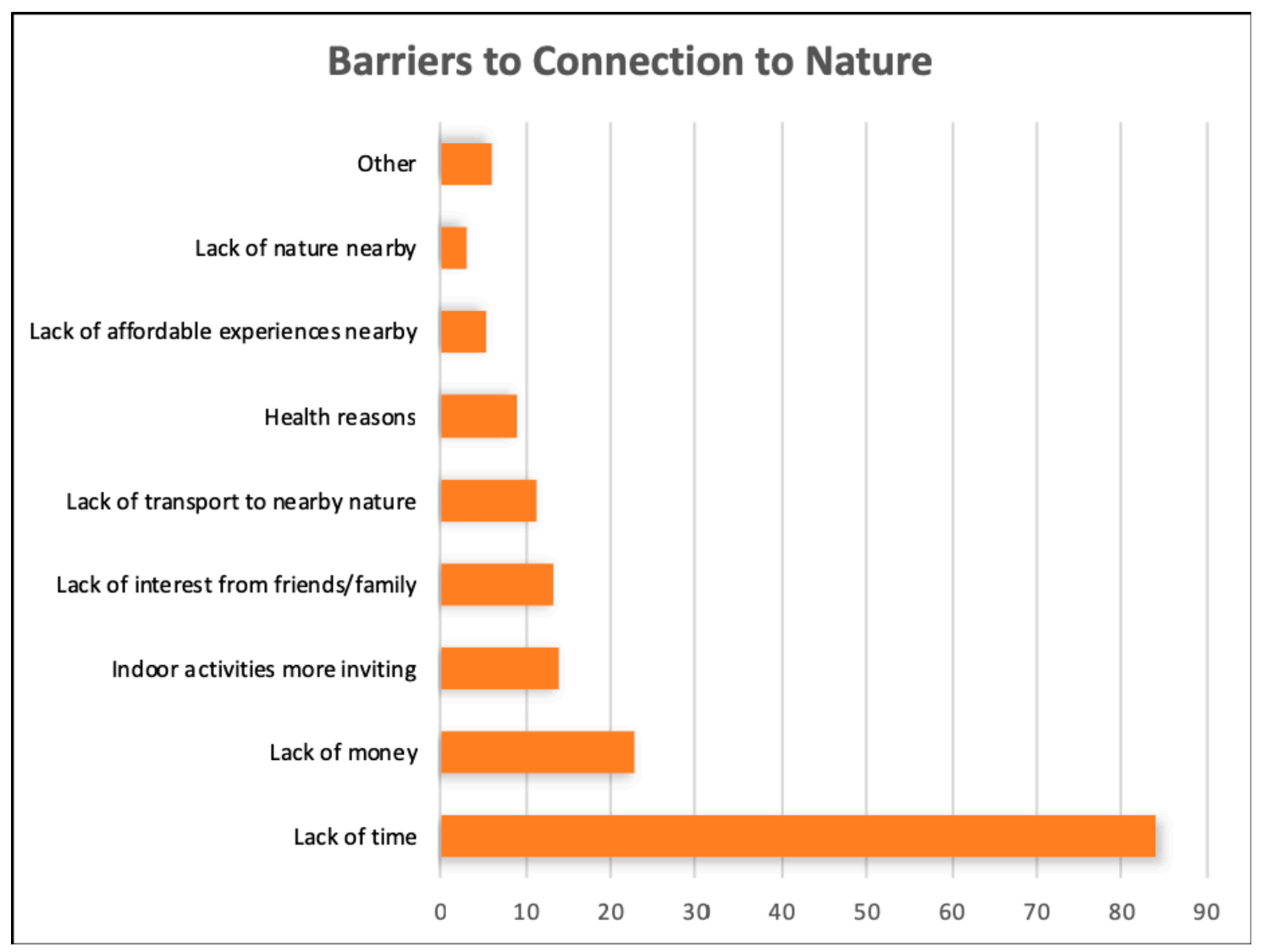

Figure 7. Perceived barriers to CTN.

\section{Discussion}

\subsection{The Relationship between Individual's Self-Reported Connection to Nature and Personal Well-Being}

Correlation analysis revealed a limited relationship between CTN and PWB. NR scores were significantly correlated with the eudemonic indicator of 'feeling that the things you do in life are worthwhile', but not with hedonic indicators (life satisfaction, happiness, and anxiety). NR-self (reflecting internalized thoughts and feelings relating to one's personal relationship with nature) [16] was found to be the key component in the association between CTN and feeling worthwhile. Potential reasons for this will be explored in relation to qualitative responses below. With regards to hedonic well-being, lack of correlation may be explained by Capaldi, Dopko and Zelenski [26], who previously hypothesized that there may not be a measurable relationship with CTN, due to the fact that CTN is strongly linked to ecological concern, which can cause feelings of distress, guilt, anger, or fear. They claim it is possible that these negative processes cancel out any positive effects of CTN.

To the authors' knowledge, the Office for National Statistics' [24] indicators of PWB have not been examined in relation to CTN before, therefore, comparing this study with past research on the topic is problematic. Nonetheless, Tam [17] found strong convergence validity across existing measures and suggests CTN and PWB be considered as broad, latent constructs. The results of this study are similar to those of Cervinka, Roderer and Hefler [13] who found significant correlation between CTN and eudemonic meaningfulness (of which feeling worthwhile is a factor) but not with hedonic measures of PWB. Conversely, the present study was not able to replicate other research findings that demonstrate clear links between CTN and hedonic dimensions of PWB such as life satisfaction or positive moods (e.g., [12,15]). Capaldi, Dopko and Zelenski [26] previously exposed significant variation in the associations between $\mathrm{CTN}$ and PWB across these studies, with correlation coefficients ranging from -0.01 to 0.42 . 
From this study alone, it would seem there is a link between feeling a sense of oneness with nature and feeling worthwhile, but not between overall CTN and hedonic aspects of PWB such as life satisfaction and happiness. However, it is difficult to draw any firm conclusions given such inconsistencies in the past research. Although the sample size of this study was comparable to, or greater than, those of previous studies on the topic (e.g., [12,14,15]), the quantitative results are similarly weak due to the non-representative sample. Statistical significance for example, is best considered as a measure of the relative strength of a relationship. Further, the nature of self-reporting brings up potential bias issues that were discussed in Section 2.5.

Sample diversity may account for much of the variance. Only this study and that conducted by Cervinka, Roderer and Hefler [13] were conducted in Europe. These report many common associations which are not found in work undertaken in other parts of the world. Sample bias may also have affected correlations in this study, as participants had much lower PWB than the UK national averages [39] and particularly high levels of anxiety. Furthermore, average NR scores in this study were high $(\mathrm{m}=4.04$ out of 5$)$, especially for NR-Perspective (reflecting an external nature-related worldview and understanding of human impacts on nature) [16]. This may be indicative of the mostly female and well-educated sample, which tend to have stronger environmental concern $[40,41]$. The fact that CTN is known to be strongly correlated with PEABs supports this $[12,16,17]$.

\subsubsection{Personal Well-Being and Nature Contact}

Nature contact was compared with PWB in order to demonstrate whether the relationship between $\mathrm{CTN}$ and PWB was distinct or related to differences in nature contact resulting from CTN. Frequency of nature contact was found to be significantly associated with feeling worthwhile, and additionally with feeling happy. Engaging in regular nature-related hobbies was associated with even greater feelings of worth and happiness than nature contact alone. This could be attributable to the additional benefits that hobbies bring, such as social connections, exercise, skill-building and recognition of achievements, for example. Correlation between NR-Self and feeling worthwhile was slightly stronger and more significant than correlations between frequency of nature contact (or hobbies) and feeling worthwhile, suggesting that feeling connected to nature might have implications for PWB above and beyond that of contact only. Recent nature contact was not found to be associated with PWB, reflecting the fact that PWB is not designed to measure momentary moods, and only sustained experiences should cause measurable changes [22].

\subsubsection{Qualitative Data}

All 158 respondents who answered a free-text question on the relationship between CTN and PWB detailed at least one positive link, however there is no way of knowing if the 64 participants who skipped the question felt that there was no link, a negative link, or they did not know whether the two concepts were linked or not. It appeared that many participants either confused or conflated connection and contact, as many discussed activities or mechanisms such as walking in nature, fresh air, and sunlight, though it is plausible that they followed a thought process along the lines of feeling more connected to nature would make one more likely to spend time in nature. A very small number of participants freely stated that CTN is linked to a sense of purpose or worth, matching the correlation found, although most discussed more short-term benefits of nature contact such as relaxation, stress relief, and soothing or calming effects. Interestingly, several participants described reductions in anxiety relating to increased CTN (which was not supported by correlation analysis), but as anxiety can be both a temporary state as well as a lasting trait, they may have been referring to the former, whilst this study considered the latter.

Six themes were identified that described mechanisms by which CTN might affect PWB (escape from modern life; time for reflection or meditation; fresh air; peace and quiet; spirituality; and sunlight). Although some were explicitly related to nature contact, others were not, and some could give insight into how NR-Self potentially increases purpose in life, or feeling worthwhile (i.e., through spirituality, 
reflection and meditation on one's personal relationship with the natural world). These themes could form the basis of future exploration into how CTN links to eudemonic well-being.

One hundred and twenty respondents felt CTN was an important contributor to PWB and the majority of these described it as very, immensely, or crucially important, with some even claiming it to be the most important factor (in comparison to diet, exercise, social life and work life etc.). Participants' confidence in the importance of CTN seems to contradict quantitative findings; however, several respondents stated that the importance of $C T N$ varies according to the individual. If individual variation in the relationship between CTN and PWB is great, it may account for the low (or absent) correlation overall, that is the effect of CTN on PWB could be very strong for some people but non-existent (or even a negative relationship) for others.

In summary, perhaps there is a relationship between CTN and PWB but it is focused on eudemonic representations of well-being, and the intricacies of the relationship vary according to each individual. A much larger, more diverse sample would be required to reduce the effects of individual variance and provide clearer understanding.

\subsection{Variables Influencing Trait-Level CTN over the Life Course?}

Demographic variables, childhood experiences, frequency of nature contact, and nature-related hobbies were all found to be potential influences on trait-level CTN over the lifespan. Pet ownership was not found to be associated with CTN. This is explored in detail below.

\subsubsection{Demographics}

It was found that all demographic variables had an impact on mean NR scores. This is in clear contrast to some of the previous findings [12,32], however they used CNS as a measure, rather than the NR scale. As NR encompasses more dimensions of CTN, there is potentially more scope for variation. There were significant differences in means when comparing different genders, age brackets, ethnicities and employment statuses. There was less variation with education level and area of residence, but still clear differences.

Females felt, on average, more connected to nature, supporting the previous theory that female tendency for greater ecological concern relates to NR scores. People who are retired or volunteers felt much more connected than students or full-time employed. This could be related to having additional time to reflect on and cultivate connection, as students and full-time employed were presumably the most time-poor. Age could also be a factor here, although those in the eldest age brackets were not as connected (on average) as those aged 55-64, so it does not correspond with typical retirement age. Area of residence related to CTN in the way one might expect, with urban dwellers feeling least connected, rural dwellers most connected, and suburban in the middle. With more time and resources, this variation could have been explored further by comparing the individual NR components against demographic variables, obtaining a more diverse sample, and perhaps collecting qualitative responses on the topic.

\subsubsection{Childhood Experiences}

Frequency of outdoor play in childhood was not found to be significantly linked to adult CTN, however, physically interacting with nature (e.g., climbing trees, digging in mud) was. NR-Experience was the most important component in the relationship between childhood experience and adult CTN, suggesting that positive nature experiences in childhood create increased desire for nature experiences as an adult, but do not necessarily provide a nature-related worldview or an internal sense of 'oneness' with nature (as these aspects were not found to be significantly correlated). This hypothesis is supported by the research of Ward Thompson, Aspinall and Montarzino [8] who found that the frequency of childhood visits to nature was a partial predictor of later adult visits. Further, qualitative responses explicitly reinforced this idea, with common themes including 'spending time outdoors' in childhood and 'increased desire for nature experiences' in adulthood. 
The identified themes could help to inform and develop existing campaigns such as The Wild Network's [20] 'rewilding childhood'. The most frequently mentioned childhood themes were 'spending time outdoors' and 'parental influence' however, these may demonstrate response bias, as a result of context effects from the phrasing of an earlier question that asked "Did your parent(s) or legal guardian(s) encourage you to play outside?". The other themes of 'seeing or interacting with wildlife'; 'walking or hiking'; 'rural upbringing'; 'physical contact with the environment (touch)'; 'forests or trees'; and 'social connections' could all potentially be incorporated into a campaign, with the exception of providing a rural upbringing. Responses could be analyzed in more depth to determine precisely which aspects of a rural upbringing were important, or why they were important, and whether that could be provided in another way. Of the adulthood themes it is interesting that several participants mentioned a desire to pass on their experiences to the next generation. It demonstrates the potential importance of childhood experiences in creating a cycle that is perpetuated.

\subsubsection{Nature in Everyday Life}

As expected, a strong and very significant relationship was observed between usual frequency of nature contact and CTN, as found in previous research $[16,17]$. This relationship is the most difficult to speculate on the causation. Does frequent nature contact cause increased CTN? Does high CTN cause increased nature contact? Do they equally affect the other, or does a third variable (or multiple variables) lead to increases in both? The fact that recent nature contact was also correlated with CTN suggests that CTN may cause contact, considering that NR scores are thought to measure a trait-like construct; however, it could be that NR scores actually picked up on state-level variance in CTN, caused by recent nature contact.

Of the three components, NR-Experience was the most correlated with nature contact, which makes perfect sense. Yet surprisingly, NR-Self was the most correlated with regular nature-related hobbies, which may reflect the aforementioned relationship that both variables have with feeling the things you do in life are worthwhile. Engaging in nature-related hobbies is obviously different to simply sitting in the garden, for example. The hobbies most associated with higher CTN were bird-watching, wildlife spotting, or volunteering for an environmental charity. Participants that did not engage in any regular nature-related hobbies had very low levels of CTN compared to the average. Again, it is difficult to ascertain causation, but future research could devise long-term intervention activities relating to bird-watching, wildlife spotting or volunteering, in order to test whether they lead to increases in CTN over time, particularly for those with no current nature-related hobbies.

Though all listed hobbies were associated with above-average CTN, cycling, walking, or running in nature were the least associated, presumably as they involve less direct contact with the natural world, or they appeal to people for other reasons. Running was the least associated of these, doubtless as it is typically focused on fitness, whereas some people engage in cycling and walking solely for pleasure, with no fitness objective. It is noted that when asking about hobbies, 'regular' was not defined, and will certainly mean different things to different people. Future studies should define 'regular', such as 'more than once a month', for example.

\subsubsection{Pet Ownership}

Unlike in the study by Nisbet, Zelenski and Murphy [16], neither childhood nor present pet ownership was found to be associated with CTN, even when accounting for desire for a pet. This is surprising not only as it conflicts with previous findings, but for the reason that animals were a common theme throughout other areas of this research. For example, participants described the importance of seeing or interacting with wildlife in childhood, and how childhood experiences encouraged a love of animals in adulthood. Also, those that regularly engaged in bird-watching or wildlife spotting had the highest NR scores on average. 


\subsection{How Do Participants Feel about CTN, with Regards to General Awareness of, Desire for, and Barriers to Connection?}

Most respondents were able to provide a definition of $\mathrm{CTN}$, prior to one being presented to them. However, participant definitions could already have been influenced by terms used in the NR Scale which came earlier in the survey. The large number of themes under which participants described CTN may reflect the fact that there is no singular definition of CTN available in the literature [17]. Most respondents could (or opted to) only describe one or two dimensions of CTN, despite NR being comprised of at least three components (NR-Self, NR-Perspective and NR-Experience) and the NR items mentioning other types of connection, such as spiritual connection. It may seem surprising that well-being was included in several definitions (e.g., "understanding how nature can affect your well-being and how you act upon that"), although this is likely explained by context effects from the four PWB indicators that came earlier in the survey, or the fact that the words 'personal well-being' actually appeared in the survey subtitle. Many respondents understood CTN to be about 'human interconnectedness with nature' or 'positive thoughts or feelings about nature' and these themes were referenced more frequently than 'enjoyment of physical experiences of nature'. This suggests that participants did understand there is a difference between connection and contact with nature.

One hundred and forty-one of 222 participants claimed to have considered CTN prior to undertaking the survey, though mostly through personal thoughts about the concept. This is a high number and gives the impression that awareness of CTN is widespread. However, as this was a non-random, non-representative sample, the fact that the majority of participants had encountered CTN (and some in an academic or work context) might reveal sample bias, in that those with greater awareness, prior interest, or strong opinions on the topic were more likely to respond to the survey request. Unfortunately, it is difficult to draw conclusions from these particular results, for that reason.

Participants were very accurate in blindly matching a single-item, self-report question asking "how connected to nature do you think you are?" with their calculated NR scores. Forty-five percent were an exact match, and the majority were close.

One hundred and eighty-eight of 222 participants claimed they wanted to be more connected to nature. When asked about the barriers to connection, $84 \%$ claimed lack of time was an important factor, which links to earlier results that showed students and people in full-time employment felt the least connected, presumably as they have the least free time. Lack of money was the second most popular reason given, so future CTN interventions could focus around brief and cheap (or free) ways to connect with the natural world. The temptation of indoor activities was also often cited as a reason, supporting past theories, (e.g., [42,43]). Thirty-four of 222 participants claimed they did not want to be more connected to nature. On average, these 34 participants had much lower NR scores, and scored lower for 'feeling worthwhile' (consistent with correlation analysis). This suggests a small percentage of people who misjudge the effects of being connected to nature. By their own admission, they 'prefer to spend their time doing other things' and 'just don't see the need to connect with nature'. This group scored higher on the other three PWB indicators though, so perhaps any eudemonic benefits of CTN were less important, as they had a greater sense of overall well-being.

\section{Conclusions}

This study explored individual's self-reported CTN at a trait-level, considering the relationship with PWB, variables that might influence CTN over the life course, and participants' awareness of, and desire for CTN. This is an important topic, given the growing concern about the spread of indoor, sedentary lifestyles, which are resulting in an increasing number of people who are physically and psychologically disconnected from the natural world.

This study revealed a significant relationship between CTN and eudemonic PWB and that this relationship may be partly distinct from that of physical nature experiences and PWB. CTN was not found to link with hedonic aspects of PWB. This is inconsistent with some of the past research on the topic (mostly focused in North America) and further study of the effects of CTN on PWB in the 
UK is recommended, particularly as the results of this study cannot be generalized due to the nature of the sample. Although CTN was not found to correlate with all measures of PWB, any impact on eudemonic well-being is important, as research has shown that hedonia and eudemonia not only influence each other but are both important for the greatest overall well-being [44].

Demographic variables, childhood experiences of nature, usual frequency of nature contact, and nature-related hobbies were all found to affect NR scores, therefore interventions targeted at relevant demographics, with an aim to alter childhood experiences, nature contact, or hobbies could prove worthwhile. Although causation could not be determined, the study found various themes which could be further explored. Most participants had some understanding of CTN and a desire to be connected. Barriers were identified which could further aid intervention research.

Lastly, some unexpected and unintended results emerged from the pilot study, before the data above was analyzed. A frequent theme emerged from the 'feedback' question of the pilot study, in that reflecting on the topic of CTN was enjoyable and enlightening, and helped participants reflect on their own relationship with nature and how it might affect their well-being, with some stating that they had never done so before (e.g., "I didn't realize what effect nature has on my life currently"; "until this survey I hadn't thought about [nature's] therapeutic effect on my life"; "the questions made me think in a way I may not have in the past"; "it highlighted to me how much I enjoy nature. I hadn't stopped to think about it before").

\section{Future Research}

This study was based on a non-random sample which was not necessarily representative, and of a particular location, the UK City of Bath. It nevertheless identifies and explores a number of useful insights into the complex relationships which exist between individual's subjective connection to nature (CTN) and aspects of their personal well-being (PWB) and environmental awareness, and therefore can be used to inform future research. For example, it is clear that there is some kind of relationship between CTN and PWB, but future research should explore the reasons for inconsistencies in the current data, and consider which factors alter the relationship between individual CTN and PWB. As the data in this study was not normally distributed, partial correlations (taking each variable into account) were not possible, and this could provide future areas of research. For example, does nature contact mediate the relationship between CTN and PWB?

As this study and one other conducted in Europe [13] produced similar findings in terms of links between CTN and eudemonic well-being (but not hedonic well-being), there may be a cultural or geographic component to this. Future research in the UK could explore more indicators of eudemonia, such as self-acceptance, mastery, positive relations, personal growth and autonomy [45] to see if the relationship is consistent.

We have limited knowledge about whether, and how, trait-level CTN alters over someone's life course. Though detailed analysis would likely involve a difficult and costly longitudinal study, there is scope for further consideration of demographic factors, childhood experiences, and nature contact within all studies of CTN. Though evidence shows a promising link between nature contact and CTN, the direction of causality is unknown, and there has been little exploration of which specific types of nature contact are most associated with CTN. Furthermore, only $5.9 \%$ of previous studies on CTN were conducted in the UK [21]. As culture and geography could conceivably affect CTN, increasing the size of the UK research pool could well be important.

None of the aforementioned studies provide a precise definition of nature itself and operationalizing the notion of nature and delineating between nature and non-nature is very difficult. There are few studies which have considered which specific aspects of nature people feel most connected to and which are associated to wellbeing. The operationalization of nature therefore remains a key gap in our understanding; both of the links between aspects of nature (as opposed to aspects of connection to nature) and wellbeing and of the challenges of cultural sustainability transformations. 
Supplementary Materials: The questionnaire used in this study is available on request from the author http:/ / www.mdpi.com/2071-1050/11/5/1386/s1.

Author Contributions: K.F. led the design and analyzed the data; A.G. supported the design and supervised the research; both wrote the paper.

Funding: This research received no specific funding for this work.

Conflicts of Interest: The authors declare no conflict of interest.

\section{References}

1. Maas, J.; Verheij, R.A.; Groenewegen, P.P.; De Vries, S.; Spreeuwenberg, P. Green space, urbanity, and health: How strong is the relation? J. Epidemiol. Community Health 2006, 60, 587-592. [CrossRef] [PubMed]

2. Maller, C.; Townsend, M.; Pryor, A.; Brown, P.; St Leger, L. Healthy nature healthy people: 'Contact with nature' as an upstream health promotion intervention for populations. Health Promot. Int. 2006, 21, 45-54. [CrossRef] [PubMed]

3. Bragg, R.; Wood, C.; Barton, J.; Pretty, J. Well-Being Benefits from Natural Environments Rich in Wildlife. A Literature Review for the Wildlife Trusts: By the University of Essex. Available online: https:/ /www.wildlifetrusts.org/sites/default/files/2018-05/r1_literature_review_wellbeing_benefits_of_wild_places_lres.pdf (accessed on 5 December 2018).

4. Cox, D.T.C.; Shanahan, D.F.; Hudson, H.L.; Fuller, R.A.; Anderson, K.; Hancock, S.; Gaston, K.J. Doses of nearby nature simultaneously associated with multiple health benefits. Int. J. Environ. Res. Public Health 2017, 14, 172. [CrossRef] [PubMed]

5. Van den Berg, A.E.; Maas, J.; Verheij, R.A.; Groenewegen, P.P. Green space as a buffer between stressful life events and health. Soc. Sci. Med. 2010, 70, 1203-1210. [CrossRef] [PubMed]

6. Beil, K.; Hanes, D. The influence of urban natural and built environments on physiological and psychological measures of stress-A pilot study. Int. J. Environ. Res. Public Health 2013, 10, 1250-1267. [CrossRef] [PubMed]

7. Roe, J.J.; Ward Thompson, C.; Aspinall, P.A.; Brewer, M.J.; Duff, E.I.; Miller, D.; Mitchell, R.; Clow, A. Green space and stress: Evidence from cortisol measures in deprived urban communities. Int. J. Environ. Res. Public Health 2013, 10, 4086-4103. [CrossRef] [PubMed]

8. Ward Thompson, C.; Aspinall, P.; Roe, J.; Robertson, L.; Miller, D. Mitigating stress and supporting health in deprived urban communities: The importance of green space and the social environment. Int. J. Environ. Res. Public Health 2016, 13, 440. [CrossRef] [PubMed]

9. Barton, J.; Griffin, M.; Pretty, J. Exercise-, nature- and socially interactive-based initiatives improve mood and self-esteem in the clinical population. Perspect. Public Health 2012, 132, 89-96. [CrossRef] [PubMed]

10. Berman, M.G.; Kross, E.; Krpan, K.M.; Askren, M.K.; Burson, A.; Deldin, P.J.; Kaplan, S.; Sherdell, L.; Gotlib, I.H.; Jonides, J. Interacting with nature improves cognition and affect for individuals with depression. J. Affect. Disord. 2012, 140, 300-305. [CrossRef] [PubMed]

11. MacKerron, G.; Mourato, S. Happiness is greater in natural environments. Glob. Environ. Change 2013, 23, 992-1000. [CrossRef]

12. Nisbet, E.K.; Zelenski, J.M.; Murphy, S.A. Happiness is in our nature: Exploring nature relatedness as a contributor to subjective well-being. J. Happiness Stud. 2011, 12, 303-322. [CrossRef]

13. Tam, K.P. Concepts and measures related to connection to nature: Similarities and differences. J. Environ. Psychol. 2013, 34, 64-78. [CrossRef]

14. Mayer, F.S.; Frantz, C.M. The connectedness to nature scale: A measure of individuals' feeling in community with nature. J. Environ. Psychol. 2004, 24, 503-515. [CrossRef]

15. Cervinka, R.; Roderer, K.; Hefler, E. Are nature lovers happy? On various indicators of well-being and connectedness with nature. J. Health Psychol. 2011, 17, 379-388. [CrossRef] [PubMed]

16. Zelenski, J.M.; Nisbet, E.K. Happiness and feeling connected: The distinct role of nature relatedness. Environ. Behav. 2014, 46, 3-23. [CrossRef]

17. Nisbet, E.K.; Zelenski, J.M.; Murphy, S.A. The nature relatedness scale: Linking individuals' connection with nature to environmental concern and behavior. Environ. Behav. 2009, 41, 715-740. [CrossRef]

18. Marques, B.; McIntosh, J.; Popoola, T. October. Green prescriptions and therapeutic landscapes: A New Zealand study. Int. J. Behav. Med. 2018, 25, S21-S22. 
19. Richardson, M.; Cormack, A.; McRobert, L.; Underhill, R. 30 days wild: Development and evaluation of a large-scale nature engagement campaign to improve well-being. PLoS ONE 2016, 11, e0149777. [CrossRef] [PubMed]

20. The Wild Network, Wild Time. Available online: https://www.thewildnetwork.com/about/ (accessed on 6 December 2018).

21. Ives, C.D.; Giusti, M.; Fischer, J.; Abson, D.J.; Klaniecki, K.; Dorninger, C.; Laudan, J.; Barthel, S.; Abernethy, P.; Martín-López, B. Human-nature connection: A multidisciplinary review. Curr. Opin. Environ. Sustain. 2017, 26-27, 106-113. [CrossRef]

22. Diener, E. Subjective well-being. Psychol. Bull. 1984, 95, 542-575. [CrossRef] [PubMed]

23. Diener, E.; Lucas, R.E.; Oishi, S. Subjective well-being: The science of happiness and life satisfaction. In The Oxford Handbook of Positive Psychology, 2nd ed.; Lopez, S.J., Snyder, C.R., Eds.; Oxford University Press: Oxford, UK, 2009; pp. 63-73.

24. Office for National Statistics, Personal Well-Being Frequently Asked Questions. Available online: https:/ / www.ons.gov.uk/peoplepopulationandcommunity/well-being/methodologies/personalwellbeingfrequentlyaskedquestions (accessed on 6 December 2018).

25. McMahan, E.A.; Estes, D. Hedonic versus eudaimonic conceptions of well-being: Evidence of differential associations with self-reported well-being. Soc. Indic. Res. 2011, 103, 93-108. [CrossRef]

26. Capaldi, C.A.; Dopko, R.L.; Zelenski, J.M. The relationship between nature connectedness and happiness: A meta-analysis. Front. Psychol. 2014, 5, 976. [CrossRef] [PubMed]

27. Wilson, E.O. Biophilia; Harvard University Press: Cambridge, MA, USA, 1984.

28. Kellert, S.R.; Wilson, E.O. (Eds.) The Biophilia Hypothesis; Island Press: Washington, DC, USA, 1993.

29. Orr, D.W. Earth in Mind: On Education, Environment, and the Human Prospect; Island Press: Washington, DC, USA, 1994.

30. Schultz, W.P. The structure of environmental concern: Concern for self, other people, and the biosphere. J. Environ. Psychol. 2001, 21, 327-339. [CrossRef]

31. Perrin, J.L.; Benassi, V.A. The connectedness to nature scale: A measure of emotional connection to nature? J. Environ. Psychol. 2009, 29, 434-440. [CrossRef]

32. Klassen, M.J. Connectedness to Nature: Comparing Rural and Urban Youths' Relationships with Nature. Master's Thesis, Royal Roads University, Victoria, BC, Canada, 2010.

33. Ward Thompson, C.; Aspinall, P.; Montarzino, A. The childhood factor: Adult visits to green places and the significance of childhood experience. Environ. Behav. 2008, 40, 111-143. [CrossRef]

34. Smyth, J.; Terry, C.P. Self-Report. In Encyclopedia of Measurement and Statistics; Salkind, N.J., Ed.; Sage Publications: Thousand Oaks, CA, USA, 2011; 878p.

35. Roberts, K. Convenience sampling through Facebook. In SAGE Research Methods Cases; SAGE Publications Ltd.: London, UK, 2014.

36. IBM Corp. IBM SPSS Statistics for Windows; Version 24.0.; IBM Corp: New York, NY, USA, 2016.

37. Hsieh, H.-F.; Shannon, S.E. Three approaches to qualitative content analysis. Qual. Health Res. 2005, 15, 1277-1288. [CrossRef] [PubMed]

38. Nature Relatedness Research, Nature Relatedness Scale and Scoring. Available online: http://www. naturerelatedness.ca/Nature_Relatedness.html (accessed on 6 December 2018).

39. Office for National Statistics, Personal Well-Being in the UK: 2015 to 2016. Available online: https: / / www. ons.gov.uk/releases/personalwell-beingintheuk2015to2016 (accessed on 6 December 2018).

40. Zelezny, L.C.; Chua, P.-P.; Aldrich, C. New Ways of Thinking about Environmentalism: Elaborating on Gender Differences in Environmentalism. J. Soc. Issues 2000, 56, 443-457. [CrossRef]

41. Clery, E.; Rhead, R. Education and Attitudes Towards the Environment. UNESCO Background Paper Prepared for the Education for All Global Monitoring Report 2013. Available online: http:/ / unesdoc.unesco. org/images/0022/002259/225928E.pdf (accessed on 6 December 2018).

42. Balmford, A.; Cowling, R.M. Fusion or failure? The future of conservation biology. Conserv. Biol. 2006, 20, 692-695. [CrossRef]

43. National Trust, Natural Childhood Report. Available online: https:/ /www.nationaltrust.org.uk/documents / read-our-natural-childhood-report.pdf (accessed on 6 December 2018). 
44. Huta, V.; Ryan, R.M. Pursuing pleasure or virtue: The differential and overlapping well-being benefits of hedonic and eudaimonic motives. J. Happiness Stud. 2009, 11, 735-762. [CrossRef]

45. Ryff, C.D.; Keyes, C.L.M. The structure of psychological well-being revisited. J. Personal. Soc. Psychol. 1995, 69, 719-727. [CrossRef]

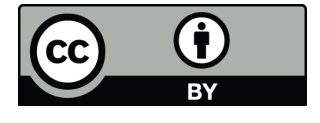

(C) 2019 by the authors. Licensee MDPI, Basel, Switzerland. This article is an open access article distributed under the terms and conditions of the Creative Commons Attribution (CC BY) license (http:/ / creativecommons.org/licenses/by/4.0/). 